\title{
Is There a Difference in Total Knee Arthroplasty Risk of Revision in Highly Crosslinked versus Conventional Polyethylene?
}

\author{
Elizabeth W. Paxton MA, Maria C. S. Inacio PhD, \\ Steven Kurtz PhD, Rebecca Love MPH, RN, \\ Guy Cafri PhD, Robert S. Namba MD
}

Published online: 8 January 2015

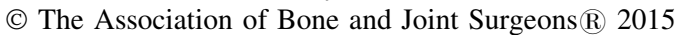

\begin{abstract}
Background Highly crosslinked polyethylene (HXLPE) was introduced to reduce wear and associated osteolysis in total knee arthroplasty (TKA). However, there is limited clinical evidence that HXLPE is more effective than conventional polyethylene (CPE) in TKA.

Questions/purposes (1) Do primary TKAs with HXLPE tibial inserts have a lower risk of revision (all-cause,
\end{abstract}

\begin{abstract}
One of the authors (SK) is an employee and shareholder of Exponent, Inc (Menlo Park, CA, USA) and received institutional support as a Principal Investigator from Smith \& Nephew (Memphis, TN, USA), Stryker (Mahwah, NJ, USA), Zimmer (Warsaw, IN, USA), Biomet (Warsaw, IN, USA), DePuy Synthes (Warsaw, IN, USA), Medtronic (Memphis, TN, USA), Invibio (Thornton Cleveleys, UK), Stelkast (McMurray, PA, USA), Formae (Paoli, PA, USA), Kyocera Medical (Kyoto, Japan), Wright Medical Technology (Memphis, TN, USA), Ceramtec (Plochingen, Germany), DJO (Vista, CA, USA), Celanese (Florence, KY, USA), Aesculap (Tuttlingen, Germany), Spinal Motion (Mountain View, CA, USA), and Active Implants (Memphis, TN, USA), outside the submitted work.

All ICMJE Conflict of Interest Forms for authors and Clinical Orthopaedics and Related Research ${ }^{\circledR}$ editors and board members are on file with the publication and can be viewed on request.

Clinical Orthopaedics and Related Research ${ }^{\mathbb{R}}$ neither advocates nor endorses the use of any treatment, drug, or device. Readers are encouraged to always seek additional information, including FDA-approval status, of any drug or device prior to clinical use. Each author certifies that his or her institution approved the human protocol for this investigation, that all investigations were conducted in conformity with ethical principles of research, and that informed consent for participation in the study was obtained.
\end{abstract}

E. W. Paxton ( $₫)$, M. C. S. Inacio, R. Love, G. Cafri

Surgical Outcomes and Analysis, Kaiser Permanente, 8954 Rio

San Diego Drive, Suite 406, San Diego, CA 92108, USA

e-mail: Elizabeth.w.paxton@kp.org; liz.w.paxton@kp.org

S. Kurtz

Drexel University, and Exponent, Inc, Philadelphia, PA, USA aseptic, and septic) than TKAs with CPE tibial inserts? (2) In NexGen TKA (Zimmer Inc, Warsaw, IN, USA) bearings, do HXLPE tibial inserts have a lower risk of revision (all-cause, aseptic, and septic) than CPE tibial inserts? (3) In Press-Fit Condylar TKA (PFC or PFC Sigma; DePuy Inc, Warsaw, IN, USA), do HXLPE tibial inserts have a lower risk of revision (all-cause, aseptic, and septic) than procedures performed with CPE tibial inserts? Methods The Kaiser Permanente Total Joint Replacement Registry was used to identify primary TKAs $(\mathrm{N}=77,084)$ performed during the study period (April 2001 to December 2011) with cobalt-chromium alloy on CPE (CoCr-CPE) and CoCr-HXLPE bearings. The registry has $95 \%$ voluntary participation and less than $9 \%$ were loss to followup during the 10 -year study period. A total of 60,841 (79\%) had CoCr-CPE bearings, 11,048 (14\%) had CoCr-HXLPE bearings, and 5195 (7\%) were unknown. Specific knee implant designs (NexGen, Zimmer and PFC-Sigma, DePuy Inc) were also evaluated. These implants represented $41 \%(31,793)$ and $49 \%$ $(37,457)$, respectively, of the 77,084 TKAs of known implant types registered during that period; implant selection was at the discretion of the attending surgeon. Descriptive statistics and marginal Cox regression models with propensity score adjustments were applied to compare risk of revision for CoCr-CPE versus CoCr-HXLPE TKA bearings.

R. S. Namba

Department of Orthopedic Surgery, Kaiser Permanente, Irvine, CA, USA 
Results At 5 years followup, cumulative incidence of revision for CoCr-CPE and CoCr-XLPE were $2.7 \%$ and $3.1 \%$, respectively. Adjusted risks of all-cause (hazard ratio $[\mathrm{HR}], 1.05 ; 95 \%$ confidence interval $[\mathrm{CI}], 0.86-1.29$; $\mathrm{p}=0.620)$, aseptic (HR, 1.01; 95\% CI, 0.77-1.32; $\mathrm{p}=0.954)$, and septic revision (HR, 1.11; 95\% CI, 0.81$1.51 ; \mathrm{p}=0.519)$ did not differ in patients with $\mathrm{CoCr}-$ XLPE bearings compared with CoCr-CPE. Within TKAs with NexGen components, the adjusted risks of all-cause (HR, 1.14; 95\% CI, 0.86-1.51; $\mathrm{p}=0.354$ ), aseptic (HR, 1.14; 95\% CI, 0.79-1.65; $\mathrm{p}=0.493$ ), and septic revision (HR, 1.14; 95\% CI, 0.76-1.73; $\mathrm{p}=518$ ) were similar in patients with CoCr-XLPE compared with those with $\mathrm{CoCr}$ CPE bearings. Finally, within the TKAs with PFC components, the adjusted risks of all-cause (HR, $0.80 ; 95 \% \mathrm{CI}$, $0.49-1.30 ; \mathrm{p}=0.369$ ), aseptic (HR, 0.62; 95\% CI, 0.62$1.14 ; \mathrm{p}=0.123$ ), and septic revision (HR, $0.97 ; 95 \% \mathrm{CI}$, $0.51-1.85 ; \mathrm{p}=0.929)$ were also similar in patients with CoCr-XLPE compared with those with $\mathrm{CoCr}-\mathrm{CPE}$ bearings.

Conclusions In this large study, we did not find differences in risk of revision for CoCr-HXLPE compared with CoCr-CPE bearings at 5 years followup. In selecting HXLPE in TKA, clinicians should consider the increased cost and lack of available evidence of performance for greater than 10 years followup. Future studies are necessary to evaluate longitudinal outcomes of CoCr-HXLPE versus conventional TKA bearings.

Level of Evidence Level III, therapeutic study.

\section{Introduction}

Polyethylene wear and associated osteolysis are common reasons for TKA revision. With increased demand for TKA, especially in younger patients, prevention of wear is an area of focus for technological advancement. Highly crosslinked polyethylene (HXLPE) was introduced in the 1990s with the specific aim of reducing wear in total joint arthroplasty [12]. Within total hip arthroplasty (THA), HXLPE has demonstrated reduced radiological wear $[12,13,17]$ and decreased risk of revision versus conventional polyethylene, which is defined as having been exposed only to a standard dose of gamma radiation during sterilization (at a dose of 25-40 kGy) [1-4, 20, 25]. For TKAs, the evidence is less clear regarding the beneficial effects of HXLPE over conventional polyethylene tibial liners. In vitro TKA simulation studies suggest less wear in HXLPE versus conventional polyethylene [15, 18, 19]. Based on these findings, it has been postulated that HXLPE tibial liners should offer reduction in wear within TKAs. However, differences in articulation and wear mechanisms in TKAs versus THAs must be considered $[6,26]$.
In addition, few clinical studies have examined the effect of HXLPE versus conventional polyethylene tibial liners on TKA revision. One small $(\mathrm{n}=100)$ retrospective case series reported no difference in HXLPE versus conventional polyethylene TKA revision rates at an average of 79 months followup [6]. An additional consecutive case series $(n=202)[16]$ also did not find differences in conventional polyethylene versus HXLPE TKAs in revision rates, osteolyisis, Knee Society scores, range of motion, or alignment at minimum 2 years followup. Although these studies suggest that HXLPE may be comparable to conventional polyethylene in TKA, the findings are limited as a result of small sample sizes, short-term followup, study attrition, and lack of generalizability as a result of singleinstitutional study designs. Larger, population-based studies have reported inconsistent results in TKA. Inacio et al. [9] did not find a difference in cobalt-chromium $(\mathrm{CoCr})$ HXLPE versus conventional polyethylene TKA bearings in a large $(n=62,177)$ US sample. However, a recent report from the Australian registry [4] found a lower risk of revision for HXLPE versus conventional polyethylene. The limited number of clinical studies, heterogeneity in implant designs, and inconsistent findings suggest the need for further investigation of the performance of HXLPE tibial inserts in TKAs.

This study therefore attempts to answer the following questions: (1) Do primary TKAs with HXLPE tibial inserts have a lower risk of revision (all-cause, aseptic, and septic) than TKAs with conventional polyethylene tibial inserts? (2) In NexGen TKA (Zimmer Inc, Warsaw, IN, USA) bearings, do HXLPE tibial inserts have a lower risk of revision (all-cause, aseptic, and septic) than conventional polyethylene tibial inserts? (3) In Press-Fit Condylar TKA (PFC or PFC Sigma; DePuy Inc, Warsaw, IN, USA), do HXLPE tibial inserts have a lower risk of revision (all-cause, aseptic, and septic) than procedures performed with conventional polyethylene tibial inserts?

\section{Patients and Methods}

\section{Study Design and Setting}

A retrospective cohort study was conducted. The Kaiser Permanente total joint replacement registry (TJRR) was used to identify primary TKAs performed within the study period (April 1, 2001, to December 31, 2011). Data collection procedures, participation, and coverage of this TJRR have been published $[22,24]$. In brief, the TJRR covers over 9 million members of an integrated healthcare system in seven geographical regions in the United States and enrolls over 20,000 joint arthroplasties a year. 
Participation in the registry is voluntary with a $95 \%$ participation rate. During the study period there was minimal loss to followup $(9 \%, \mathrm{n}=7127)$. An additional $6 \%(\mathrm{n}=4532)$ died during the study period [23]. Patients who died had on average $3.5(\mathrm{SD}=2.3$ ) years of followup before the event and patients who were lost to followup had 2.2 years $(\mathrm{SD}=1.9$ ) of followup.

\section{Participants/Study Subjects}

Inclusion criteria included elective primary TKAs, osteoarthritis as the primary diagnosis, patients aged 18 years or older at the time of their procedure, CoCr alloy on HXLPE (CoCr-HXLPE), or CoCr-conventional polyethylene knee bearings. Patients with revision procedures, unicompartmental or bicompartmental knee arthroplasties, conversion procedures, or with oxidized zirconium-conventional polyethylene or oxidized zirconium-HXLPE bearings were not included in the study. The study sample $(\mathrm{N}=77,084)$ included all implant designs and had a mean followup of 3.4 years $(\mathrm{SD}=2.5)$; the NexGen $(\mathrm{N}=31,793$, mean followup 3.5 years $[\mathrm{SD}=2.6])$ and PFC $(\mathrm{N}=37,457$, mean followup 3.3 years $[\mathrm{SD}=2.5]$ ) subsamples together made up approximately $90 \%$ of the overall sample. In the overall sample, $14.3 \%(\mathrm{n}=11,048)$ had CoCr-HXLPE bearings. In the NexGen group 20.4\% ( $n=6473)$ had CoCr-HXLPE and in the PFC-Sigma it was $6.1 \%$ $(\mathrm{n}=2291)$. TKA cases from 51 medical centers and 412 surgeons were included.

\section{Description of Treatment}

The type of polyethylene tibial insert used in conjunction with a $\mathrm{CoCr}$ alloy femoral bearing was the exposure of interest in this study (CoCr-conventional polyethylene versus CoCr-HXLPE). Information regarding tibial insert material and femoral component material was obtained from the TJRR.

The HXLPE formulations differ between manufacturers. For the NexGen TKA design, the HXLPE formulation is known as Prolong and is electron beam-crosslinked with $65 \mathrm{kGy}$, remelted, and gas plasma-sterilized. For the PFC/ PFC Sigma TKA design, the HXLPE formulation is XLK and is gamma radiation-crosslinked with $50 \mathrm{kGy}$, remelted, and gas plasma-sterilized [10].

\section{Description of Followup Routine}

This was an observational study; therefore, no specific followup routine was prescribed as part of the study protocol. Followup was performed as part of routine care in the practices of the surgeons whose patients' data were captured in the registry.

Variables, Outcome Measures, and Bias

Revision procedure was the outcome of interest. All-cause revision included procedures for any reason during which removal and reimplantation of a component occurred at any time after the original index procedure. Aseptic revision was defined as a revision for noninfectious reasons any time after the original index procedure. Septic revision was defined as revision for infection any time after the original procedure. The TJRR prospectively monitors all registered cases for subsequent revisions. After identification of a possible revision case by the registry, through electronic algorithms or surgeon reporting, the cases were reviewed by trained clinical research experts (see Acknowledgments) who adjudicated the events and confirmed the reasons for revision.

Variables thought to be associated with both the bearingsurface category assignment (conventional polyethylene versus HXLPE) and survival of the TKA were used in a model that adjusted for confounding using propensity score weights. The variables included continuous covariates for age, operative time, body mass index (BMI), surgeon volume, hospital volume, number of procedures performed by the surgeon with a specific bearing combination, and categorical covariates for sex, American Society for Anesthesiologists (ASA) score (two categories) [21], diabetes diagnosis, race (five categories), implant fixation (three categories), bilateral procedure, implant design mobility (fixed versus rotating), stability (posterior-stabilized versus cruciate-retaining versus low contact stress), and surgeon total joint arthroplasty fellowship training status. Additionally, final models were adjusted for high flexion implant design (which could not be included in propensity scores calculation as a result of imbalance between the groups).

\section{Statistical Analysis}

Frequencies, proportions, means and SDs as well as medians and interquartile ranges are used to describe the overall sample and the NexGen and PFC subsamples by the bearing surface groups. Student's t-test and chisquare tests were used to compare the descriptive statistics depending on data type. Crude cumulative incidence of all-cause, aseptic, and septic revision, revision rate/100 years of observation (revision density), and reasons for revision were also studied for the overall 
sample and by subsamples. Overall comparisons of crude cumulative incidence of revision were performed using chi square tests, and revision rate/100 years of observation was compared using a Poisson regression model.

Because tibial insert material was not randomly assigned, we addressed possible confounding using a weighted propensity score approach [7,8]. The objective for using propensity scores was to remove or reduce confounding so the magnitude of bias in the estimated treatment effect was negligible. Propensity score methods can minimize confounding by making the treatment groups equal (or approximately so) on a collection of measured variables. The fundamental theoretical property of propensity score methods is that cases with the same correctly estimated propensity scores will be comparable with respect to all covariates used to calculate the propensity scores, so that it is only a matter of chance as to whether each actually receives one treatment or the other. In the specific approach used, the following steps were taken: (1) the propensity score was estimated in the conventional way by fitting a logistic regression model and estimating the conditional probability of treatment assignment for each record; (2) we checked that cases in one bearing group had comparable counterparts with respect to their covariate distribution in the other bearing group; those that did not were excluded based on a caliper width of $0.2 \mathrm{SD}$ of the logit propensity score; (3) we stratified the sample into six strata based on the estimated logit propensity score; and (4) we calculated the weight for each record based on the number of units in a stratum multiplied by the proportion of units assigned to the treatment group of interest in the data and divided by the number of records assigned to the treatment group of interest in that particular stratum. Missing data were handled using multiple imputation. Ten imputed data sets were created and Rubin's rules for aggregating parameter estimates and variances were used [27]. Marginal multivariate Cox regression models adjusting standard errors for surgeon clustering were fit with propensity score weights for each imputed data set and results were subsequently aggregated across data sets [14]. All analyses used CoCr-conventional polyethylene as the reference group. Hazard ratios (HRs) and 95\% confidence intervals (CIs) and Wald $\mathrm{p}$ values are provided. For the analysis models, individuals not experiencing a revision, terminating membership, or dying before experiencing a revision were censored and survival was calculated as the time from surgery to each of these alternative events. Data were analyzed using SAS (Version 9.2; SAS Institute, Cary, NC, USA), and alpha $=0.05$ was used as the threshold for statistical significance.
Demographics and Description of Study Population

The majority of the 77,084 primary TKAs included in the study were women $(\mathrm{n}=48,035[62 \%])$, white $(\mathrm{n}=52,595$ [68\%]), had a BMI of $30 \mathrm{~kg} / \mathrm{m}^{2}$ or greater $(\mathrm{n}=42,699$ [55\%]), and had an ASA score of 1 or $2(n=45,252$ [59\%]) at the time of their surgery (Table 1). The average age of the cohort was 68 years old $(\mathrm{SD}=9)$, and the prevalence of diabetes was $30 \%(n=22,910)$. PFC components were used in $49 \%(n=37,457)$ of the total sample and NexGen components were used in $41 \%(\mathrm{n}=31,793)$ (Table 2).

\section{Results}

Overall TKA Revision Risk: HXLPE versus Conventional

The cumulative incidence of revision for CoCRconventional polyethylene and CoCr-XLPE was $2.7 \%$ versus $3.1 \%$ at 5 years follow-up (Fig. 1). The adjusted risks of all-cause (HR, 1.05; 95\% CI, 0.86-1.29; $\mathrm{p}=0.620)$, aseptic (HR, 1.01; 95\% CI, 0.77-1.32; $\mathrm{p}=0.954$ ), and septic revision (HR, 1.11; 95\% CI, 0.81$1.51 ; \mathrm{p}=0.519)$ were not higher in patients with $\mathrm{CoCr}$ XLPE bearings compared with CoCr-conventional polyethylene (Table 3). The main reasons for revision in the CoCr-conventional polyethylene group were infection $(41 \%)$, instability (18\%), pain (19\%), and aseptic loosening $(16 \%)$. The main reasons for revision in the CoCr-XLPE group were infection (43\%), instability (26\%), pain (19\%), and arthrofibrosis (12\%) (Table 4). No revisions resulting from tibial insert dislodgement, fracture, fatigue failure, or dislocation were observed.

\section{NexGen TKA Revision Risk: HXLPE versus \\ Conventional Polyethylene Tibial Inserts}

The cumulative incidence of revision for CoCRconventional polyethylene and CoCr-XLPE was $2.5 \%$ versus $3.2 \%$ at 5 years follow-up (Fig. 2). The adjusted risks of all-cause (HR, 1.14; 95\% CI, 0.86-1.51; $\mathrm{p}=0.354)$, aseptic (HR, 1.14; 95\% CI, 0.78-1.65; $\mathrm{p}=0.493$ ), and septic revision (HR, 1.14; 95\% CI, 0.76$1.72 ; \mathrm{p}=0.518$ ) were not higher in patients with $\mathrm{CoCr}-$ XLPE compared with those with CoCr-conventional polyethylene bearings (Table 3). The main reasons for revision in the $\mathrm{CoCr}$-conventional polyethylene group were infection (42\%), aseptic loosening (19\%), instability $(18 \%)$, and pain $(17 \%)$. The main reasons for revision in 
Table 1. Primary TKA overall sample description by bearing surface

\begin{tabular}{|c|c|c|c|c|c|}
\hline Variables & & Total* & HXLPE & Conventional polyethylene & $\mathrm{p}$ value \\
\hline & & $77,084(100)$ & $11,048(14.3)$ & $60,841(78.9)$ & \\
\hline Age (years), mean (SD) & & $68(9)$ & $66(9)$ & $68(9)$ & $<0.001$ \\
\hline \multirow[t]{2}{*}{ Sex } & Males & $29,049(37.7)$ & $4215(38.2)$ & $22,767(37.4)$ & 0.144 \\
\hline & Females & $48,035(62.3)$ & $6833(61.8)$ & $38,074(62.6)$ & \\
\hline \multirow[t]{3}{*}{ ASA category } & 1 and 2 & $45,252(58.7)$ & $6330(57.3)$ & $35,798(58.8)$ & 0.789 \\
\hline & $\geq 3$ & $29,864(38.7)$ & $4181(37.8)$ & $23,782(39.1)$ & \\
\hline & Unknown & $1968(2.6)$ & 537 (4.9) & $1261(2.1)$ & \\
\hline \multirow[t]{4}{*}{ BMI category $\left(\mathrm{kg} / \mathrm{m}^{2}\right)$} & $<30$ & $33,227(43.1)$ & $4327(39.2)$ & $26,492(43.5)$ & $<0.001$ \\
\hline & $30-34$ & $22,517(29.2)$ & $3304(29.9)$ & $17,690(29.1)$ & \\
\hline & $\geq 35$ & $20,182(26.2)$ & $3321(30.1)$ & $15,692(25.8)$ & \\
\hline & Unknown & $1158(1.5)$ & $96(0.9)$ & 967 (1.6) & \\
\hline \multirow[t]{6}{*}{ Race } & Asian & $4023(5.2)$ & $429(3.9)$ & $3364(5.5)$ & $<0.001$ \\
\hline & Black & $5996(7.8)$ & $1172(10.6)$ & $4553(7.5)$ & \\
\hline & White & $52,595(68.2)$ & $7624(69)$ & $41,172(67.7)$ & \\
\hline & Hispanic & $9990(13)$ & $1333(12.1)$ & $8037(13.2)$ & \\
\hline & Other and multi & $1293(1.7)$ & $164(1.5)$ & $1063(1.7)$ & \\
\hline & Unknown & $3187(4.1)$ & $326(3.0)$ & $2652(4.4)$ & \\
\hline Diabetes & & $22,910(29.7)$ & $3292(29.8)$ & $18,138(29.8)$ & 0.975 \\
\hline Bilateral & & $6466(8.4)$ & $738(6.7)$ & $5242(8.6)$ & $<0.001$ \\
\hline \multirow[t]{4}{*}{ Fixation } & Uncemented & $2349(3)$ & $235(2.1)$ & $1334(2.2)$ & $<0.001$ \\
\hline & Hybrid & $4025(5.2)$ & $706(6.4)$ & $3171(5.2)$ & \\
\hline & Cemented & $66,628(86.4)$ & $9465(85.7)$ & $53,251(87.5)$ & \\
\hline & Unknown & $4082(5.3)$ & $642(5.8)$ & $3085(5.1)$ & \\
\hline \multirow[t]{6}{*}{ Implant mobility/stability } & Fixed: PS & $43,842(56.9)$ & $6037(54.6)$ & $37,384(61.4)$ & $<0.001$ \\
\hline & Rotate: PS & $5225(6.8)$ & $0(0.0)$ & $5207(8.6)$ & \\
\hline & Rotate: LCS & $19(<0.1)$ & $0(0.0)$ & $0(0.0)$ & \\
\hline & Rotate: CR & $962(1.2)$ & $0(0.0)$ & $960(1.6)$ & \\
\hline & Fixed: CR & $21,401(27.8)$ & $5011(45.4)$ & $16,225(26.7)$ & \\
\hline & Unknown & $5635(7.3)$ & $0(0.0)$ & $1065(1.8)$ & \\
\hline High flexion design & & $12,082(15.7)$ & $5234(47.4)$ & $6598(10.8)$ & $<0.001$ \\
\hline \multirow[t]{3}{*}{ Main femoral components } & PFC Sigma & $37,457(48.6)$ & $2291(20.7)$ & $32,367(53.2)$ & $<0.001$ \\
\hline & Nexgen & $31,793(41.2)$ & $6473(58.6)$ & $24,188(39.8)$ & \\
\hline & Other & $7834(10.2)$ & $2284(20.7)$ & $4286(7.0)$ & \\
\hline Surgeon TJA fellowship training & & $28,499(37.0)$ & $3788(34.3)$ & $22,891(37.6)$ & $<0.001$ \\
\hline \multirow[t]{3}{*}{ Surgeon volume, cases/year } & $<10$ & $1278(1.7)$ & $240(2.2)$ & $944(1.6)$ & $<0.001$ \\
\hline & $10-49$ & $30,309(39.3)$ & 4385 (39.7) & $24,133(39.7)$ & \\
\hline & $\geq 50$ & $45,497(59.0)$ & $6423(58.1)$ & $35,764(58.8)$ & \\
\hline \multirow[t]{3}{*}{ Site volume, cases/year } & $<100$ & $2060(2.7)$ & $788(7.1)$ & $1206(2.0)$ & $<0.001$ \\
\hline & $100-199$ & $14,159(18.4)$ & 1505 (13.6) & $12,042(19.8)$ & \\
\hline & $\geq 200$ & 60,865 (79) & $8755(79.2)$ & $47,593(78.2)$ & \\
\hline Number of procedures by surgeon, mean (SD) & & $180(205.3)$ & $90(108.7)$ & $205.5(217.6)$ & $<0.001$ \\
\hline Operative time, minutes, mean (SD) & & $94.6(32.5)$ & $95.5(31.7)$ & $94.7(32.7)$ & 0.023 \\
\hline
\end{tabular}

* Missing tibial insert material information $(\mathrm{N}=5195)$; TKA = total knee arthroplasty; HXLPE = highly crosslinked polyethylene; ASA = American Society of Anesthesiologists score; BMI = body mass index; TJA = total joint arthroplasty; PS = posterior-stabilized; LCS $=$ low contact stress; $\mathrm{CR}=$ cruciate-retaining; $\mathrm{PFC}=$ Press-Fit Condylar. 
Table 2. Primary TKA sample description by main femoral component group and bearing surface

\begin{tabular}{|c|c|c|c|c|c|c|c|c|c|}
\hline \multirow[t]{2}{*}{ Variables } & & \multicolumn{4}{|c|}{ Zimmer NexGen } & \multicolumn{4}{|c|}{ DePuy PFC-Sigma } \\
\hline & & Total* & HXLPE & $\begin{array}{l}\text { Conventional } \\
\text { polyethylene }\end{array}$ & $\mathrm{p}$ value & Total* & HXLPE & $\begin{array}{l}\text { Conventional } \\
\text { polyethylene }\end{array}$ & $\mathrm{p}$ value \\
\hline \multirow{2}{*}{$\begin{array}{l}\text { Age (years), } \\
\text { mean (SD) }\end{array}$} & & $68(9)$ & $66(9)$ & $69(9)$ & $<0.001$ & $68(9)$ & $68(9)$ & $67(9)$ & $<0.001$ \\
\hline & & $31,793(100)$ & $6473(20.4)$ & $24,188(76.1)$ & & $37,457(100)$ & $2291(6.1)$ & 32,367 (86.4) & \\
\hline \multirow[t]{2}{*}{ Sex } & Males & $11,933(37.5)$ & $2384(36.8)$ & 8993 (37.2) & 0.605 & $14,061(37.5)$ & $930(40.6)$ & $12,076(37.3)$ & 0.002 \\
\hline & Females & $19,860(62.5)$ & $4089(63.2)$ & $15,195(62.8)$ & & $23,396(62.5)$ & $1361(59.4)$ & $20,291(62.7)$ & \\
\hline \multirow[t]{3}{*}{ ASA } & 1 and 2 & $19,320(60.8)$ & $3926(60.7)$ & $14,600(60.4)$ & & $21,778(58.1)$ & 1189 (51.9) & $18,944(58.5)$ & $<0.001$ \\
\hline & $\geq 3$ & 11,958 (37.6) & $2327(35.9)$ & 9314 (38.5) & & $14,727(39.3)$ & $988(43.1)$ & $12,626(39.0)$ & \\
\hline & Unknown & $515(1.6)$ & $220(3.4)$ & $274(1.1)$ & 0.012 & $952(2.5)$ & $114(5.0)$ & $797(2.5)$ & \\
\hline \multirow{4}{*}{$\begin{array}{l}\text { BMI category } \\
\left(\mathrm{kg} / \mathrm{m}^{2}\right)\end{array}$} & $<30$ & $13,880(43.7)$ & $2466(38.1)$ & $10,943(45.2)$ & & $16,235(43.3)$ & $962(42.0)$ & $13,823(42.7)$ & 0.099 \\
\hline & $30-34$ & $9131(28.7)$ & $1977(30.5)$ & $6816(28.2)$ & & $10,988(29.3)$ & $665(29.0)$ & $9538(29.5)$ & \\
\hline & $\geq 35$ & $8297(26.1)$ & $1958(30.2)$ & $6029(24.9)$ & & 9689 (25.9) & $658(28.7)$ & $8524(26.3)$ & \\
\hline & Unknown & $485(1.5)$ & $72(1.1)$ & $400(1.7)$ & $<0.001$ & $545(1.5)$ & $6(0.3)$ & $482(1.5)$ & \\
\hline \multirow[t]{6}{*}{ Race } & Asian & $1654(5.2)$ & $262(4.0)$ & $1364(5.6)$ & & $1999(5.3)$ & $88(3.8)$ & $1781(5.5)$ & $<0.001$ \\
\hline & Black & $2347(7.4)$ & 766 (11.8) & $1536(6.4)$ & & $2904(7.8)$ & $145(6.3)$ & $2649(8.2)$ & \\
\hline & White & $23,298(73.3)$ & $4292(66.3)$ & $18,068(74.7)$ & & $24,198(64.6)$ & 1778 (77.6) & $20,428(63.1)$ & \\
\hline & Hispanic & 3141 (9.9) & 890 (13.7) & $2168(9.0)$ & & $6066(16.2)$ & $193(8.4)$ & 5459 (16.9) & \\
\hline & $\begin{array}{l}\text { Other and } \\
\text { multi }\end{array}$ & 477 (1.5) & $84(1.3)$ & 380 (1.6) & & $659(1.8)$ & $35(1.5)$ & $592(1.8)$ & \\
\hline & Unknown & $876(2.8)$ & $179(2.8)$ & $672(2.8)$ & $<0.001$ & $1631(4.4)$ & $52(2.3)$ & $1458(4.5)$ & \\
\hline Diabetes & & 9173 (28.9) & 1905 (29.4) & 6989 (28.9) & & $11,540(30.8)$ & $695(30.3)$ & 9972 (30.8) & 0.636 \\
\hline Bilateral & & $2268(7.1)$ & $365(5.6)$ & $1793(7.4)$ & & $3540(9.5)$ & $172(7.5)$ & $3112(9.6)$ & 0.001 \\
\hline \multirow[t]{4}{*}{ Fixation } & Uncemented & $1666(5.2)$ & $34(0.5)$ & 905 (3.7) & & $199(0.5)$ & $7(0.3)$ & $184(0.6)$ & 0.005 \\
\hline & Hybrid & $1682(5.3)$ & $467(7.2)$ & $1198(5)$ & & $1571(4.2)$ & $126(5.5)$ & $1413(4.4)$ & \\
\hline & Cemented & $26,468(83.3)$ & $5601(86.5)$ & $20,542(84.9)$ & & $34,041(90.9)$ & 1988 (86.8) & $29,406(90.9)$ & \\
\hline & Unknown & $1977(6.2)$ & $371(5.7)$ & $1543(6.4)$ & $<0.001$ & $1646(4.4)$ & $170(7.4)$ & $1364(4.2)$ & \\
\hline \multirow{6}{*}{$\begin{array}{l}\text { Implant } \\
\text { mobility/ } \\
\text { stability }\end{array}$} & Fixed: PS & $23,020(72.4)$ & $4124(63.7)$ & $18,725(77.4)$ & & $19,240(51.4)$ & $1524(66.5)$ & $17,584(54.3)$ & $<0.001$ \\
\hline & Rotate: PS & $0(0.0)$ & $0(0.0)$ & $0(0.0)$ & & 4665 (12.5) & $0(0.0)$ & 4654 (14.4) & \\
\hline & Rotate: LCS & $0(0.0)$ & $0(0.0)$ & $0(0.0)$ & & $0(0.0)$ & $0(0.0)$ & $0(0.0)$ & \\
\hline & Rotate: CR & $0(0.0)$ & $0(0.0)$ & $0(0.0)$ & & $961(2.6)$ & $0(0.0)$ & $960(3.0)$ & \\
\hline & Fixed: CR & 7867 (24.7) & 2349 (36.3) & 5463 (22.6) & & 9978 (26.6) & 767 (33.5) & 9169 (28.3) & \\
\hline & Unknown & $906(2.8)$ & $0(0.0)$ & $0(0.0)$ & $<0.001$ & $2613(7)$ & $0(0.0)$ & $0(0.0)$ & \\
\hline $\begin{array}{l}\text { High flexion } \\
\text { design }\end{array}$ & & $10,315(32.4)$ & $4335(67.0)$ & $5801(24.0)$ & & $284(0.8)$ & $0(0.0)$ & $284(0.9)$ & $<0.001$ \\
\hline $\begin{array}{l}\text { Surgeon TJA } \\
\text { fellowship } \\
\text { training }\end{array}$ & & 10,137 (31.9) & 2616 (40.4) & 7197 (29.8) & & $15,471(41.3)$ & $294(12.8)$ & $14,064(43.5)$ & $<0.001$ \\
\hline \multirow{3}{*}{$\begin{array}{l}\text { Surgeon } \\
\text { volume, } \\
\text { cases/year }\end{array}$} & $<10$ & $723(2.3)$ & $144(2.2)$ & $538(2.2)$ & $<0.001$ & $315(0.8)$ & $41(1.8)$ & $266(0.8)$ & $<0.001$ \\
\hline & $10-49$ & $12,539(39.4)$ & 2034 (31.4) & $10,184(42.1)$ & & $14,344(38.3)$ & $1614(70.4)$ & $11,832(36.6)$ & \\
\hline & $\geq 50$ & $18,531(58.3)$ & 4295 (66.4) & $13,466(55.7)$ & & $22,798(60.9)$ & $636(27.8)$ & $20,269(62.6)$ & \\
\hline \multirow{3}{*}{$\begin{array}{l}\text { Site volume, } \\
\text { cases/year }\end{array}$} & $<100$ & $163(0.5)$ & $75(1.2)$ & $74(0.3)$ & $<0.001$ & $664(1.8)$ & $140(6.1)$ & $520(1.6)$ & $<0.001$ \\
\hline & 100-199 & $8302(26.1)$ & 1189 (18.4) & 6896 (28.5) & & 4101 (10.9) & $113(4.9)$ & 3962 (12.2) & \\
\hline & $\geq 200$ & $23,328(73.4)$ & 5209 (80.5) & $17,218(71.2)$ & & $32,692(87.3)$ & 2038 (89) & $27,885(86.2)$ & \\
\hline $\begin{array}{l}\text { Number of } \\
\text { procedures } \\
\text { by surgeon, } \\
\text { mean (SD) }\end{array}$ & & $157.1(160.4)$ & 98.8 (111.2) & 178.1 (168.6) & $<0.001$ & 212.4 (239.9) & $42.8(37.4)$ & $233.2(249.1)$ & $<0.001$ \\
\hline
\end{tabular}


Table 2. continued

\begin{tabular}{|c|c|c|c|c|c|c|c|c|}
\hline \multirow[t]{2}{*}{ Variables } & \multicolumn{4}{|c|}{ Zimmer NexGen } & \multicolumn{4}{|c|}{ DePuy PFC-Sigma } \\
\hline & Total* & HXLPE & $\begin{array}{l}\text { Conventional } \\
\text { polyethylene }\end{array}$ & $\mathrm{p}$ value & Total* & HXLPE & $\begin{array}{l}\text { Conventional } \\
\text { polyethylene }\end{array}$ & $\mathrm{p}$ value \\
\hline $\begin{array}{l}\text { Operative time, } \\
\text { minutes, } \\
\text { mean (SD) }\end{array}$ & $95.8(32.4)$ & $93.4(29.7)$ & $96.6(33)$ & $<0.001$ & $93.2(32.4)$ & $105.8(38.4)$ & $92.9(32.2)$ & $<0.001$ \\
\hline
\end{tabular}

* Missing tibial insert material information: Nexgen (1132), PFC-Sigma (2797); TKA = total knee arthroplasty; HXLPE = highly crosslinked polyethylene; ASA = American Society of Anesthesiologists score; BMI = body mass index; TJA = total joint arthroplasty; PS = posteriorstabilized; LCS = low contact stress; CR = cruciate-retaining; PFC = Press-Fit Condylar.

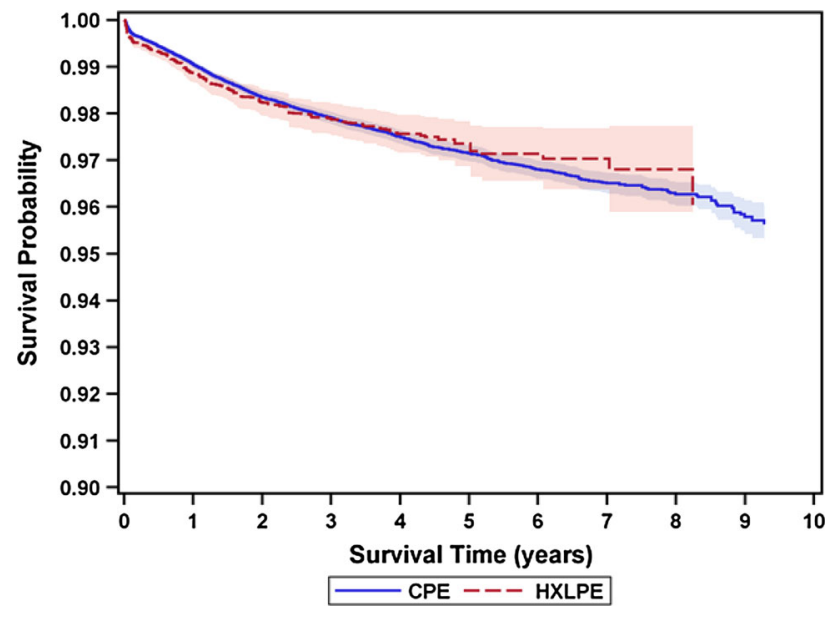

Fig. 1 Kaplan-Meier survival estimates and 95\% CIs by insert material for the overall cohort are displayed. $\mathrm{CPE}=$ conventional polyethylene, HXLPE = highly crosslinked polyethylene.

the CoCr-XLPE group were infection (41\%), instability (32\%), pain (19\%), and arthrofibrosis (11\%) (Table 4).

PFC TKA Revision Risk: HXLPE versus Conventional Polyethylene Tibial Inserts

The cumulative incidence of revision for CoCRconventional polyethylene and CoCr-XLPE was $2.8 \%$ versus $2.2 \%$ at 5 years follow-up (Fig. 3). The adjusted risks of all-cause (HR, 0.80; 95\% CI, 0.49-1.31; $\mathrm{p}=0.369$ ), aseptic (HR, 0.62; 95\% CI, 0.62-1.14; $\mathrm{p}=0.123$ ), and septic revision (HR, 0.97; 95\% CI, 0.51-1.85; $\mathrm{p}=0.929$ ) were not higher in patients with CoCr-XLPE compared with those with CoCr-conventional polyethylene bearings (Table 3). The main reasons for revision in the CoCr-conventional polyethylene group were infection (43\%), pain (19\%), instability (17\%), and aseptic loosening (16\%). The main reasons for revision in the CoCr-XLPE group were infection $(56 \%)$, pain (28\%), arthrofibrosis (16\%), and aseptic loosening (13\%) (Table 4).

\section{Discussion}

The demand for revision TKA is projected to increase by $601 \%$ by 2030 [11]. Revision TKA is a higher risk procedure with increased risk of mortality and morbidity compared with primary TKAs. Although technological innovations provide potential opportunities to reduce TKA revision rates, new technologies can also increase the risk of revision. Evidence for the introduction of these new technologies is often limited yet new implants and materials are constantly introduced into clinical practice. TKA XLPE is an example of a new technology introduced with little evidence of performance. Registries provide a unique opportunity to evaluate the introduction of these technologies in a real-world setting consisting of all types of patients, hospital settings, and surgeon skill levels. In addition, registries can also provide larger sample sizes and longer term followup typically not feasible in clinical trials. Therefore, using a large US registry, we examined the effect of HXLPE versus conventional polyethylene on risk of revision in TKA. The large, representative sample with high generalizability was a strength of our study, as well as our ability to evaluate different implant brands and the inclusion of revision as the study endpoint, which had been reviewed and adjudicated by trained clinical content experts. We found that the cumulative incidence of revision for CoCR-conventional polyethylene was $2.7 \%$ versus $3.1 \%$ for CoCr-XLPE at 5 years followup. The adjusted risks of all-cause, aseptic, and septic revision did not differ between CoCr-XLPE bearings compared with $\mathrm{CoCr}$-conventional polyethylene.

This study had several limitations. First, our study was observational in nature, and therefore it is possible that we did not address every potential confounding variable in our analyses. We attempted to address this limitation with the use of propensity scores. To assess performance of HXLPE versus conventional polyethylene between implant designs, we compared bearings within our two highest volume brands resulting in a reduced sample size for these brand-specific comparisons. Another perceived 
Table 3. Propensity score weighted regression results for risk of revision (all-cause, aseptic, and septic) in CoCr-HXLPE bearings compared with CoCr-conventional polyethylene bearings for the overall sample and by main femoral component group

\begin{tabular}{|c|c|c|c|c|c|c|}
\hline \multirow[t]{2}{*}{ Revision } & \multicolumn{2}{|l|}{ All cases } & \multicolumn{2}{|l|}{ Zimmer NexGen } & \multicolumn{2}{|l|}{ DePuy PFC-Sigma } \\
\hline & $\begin{array}{l}\text { Crude } \\
\text { HR }(95 \% \text { CI) }\end{array}$ & $\begin{array}{l}\text { Adjusted } \\
\text { HR }(95 \% \text { CI })\end{array}$ & $\begin{array}{l}\text { Crude } \\
\text { HR }(95 \% \text { CI) }\end{array}$ & $\begin{array}{l}\text { Adjusted } \\
\text { HR }(95 \% \text { CI })\end{array}$ & $\begin{array}{l}\text { Crude } \\
\text { HR }(95 \% \text { CI) }\end{array}$ & $\begin{array}{l}\text { Adjusted } \\
\text { HR }(95 \% \text { CI })\end{array}$ \\
\hline All-cause & $1.14(0.93-1.41)$ & $1.05(0.86-1.29)$ & $1.25(0.96-1.62)$ & $1.14(0.86-1.51)$ & $0.79(0.48-1.29)$ & $0.80(0.49-1.30)$ \\
\hline Aseptic & $1.19(0.91-1.56)$ & $1.01(0.77-1.32)$ & $1.38(0.95-2.00)$ & $1.14(0.79-1.65)$ & $0.58(0.30-1.11)$ & $0.62(0.33-1.14)$ \\
\hline Septic & $1.08(0.79-1.50)$ & $1.11(0.81-1.51)$ & $1.08(0.71-1.66)$ & $1.14(0.76-1.73)$ & $1.00(0.53-1.89)$ & $0.97(0.51-1.85)$ \\
\hline
\end{tabular}

$\mathrm{HXLPE}=$ highly crosslinked polyethylene; $\mathrm{CoCr}=$ cobalt-chromium; $\mathrm{HR}=$ hazard ratio; $\mathrm{CI}=$ confidence interval.

Table 4. Crude all-cause, aseptic, septic cumulative incidence of revision, revision rate per 100 years of followup, and reasons for revision for the overall sample and by main femoral component group

\begin{tabular}{|c|c|c|c|c|c|c|}
\hline \multirow[t]{2}{*}{ Specific outcomes } & \multicolumn{2}{|l|}{ All cases } & \multicolumn{2}{|l|}{ Zimmer NexGen } & \multicolumn{2}{|l|}{ DePuy PFC-Sigma } \\
\hline & HXLPE & $\mathrm{CPE}$ & HXLPE & $\begin{array}{l}\text { Conventional } \\
\text { polyethylene }\end{array}$ & HXLPE & $\begin{array}{l}\text { Conventional } \\
\text { polyethylene }\end{array}$ \\
\hline Total years of followup & 24,618 & 216,730 & 15,450 & 84,589 & 4106 & 117,182 \\
\hline \multicolumn{7}{|l|}{ All-cause revision } \\
\hline Crude incidence, number (\%) & $223(2.0)$ & $1418(2.3)$ & $140(2.2)$ & $515(2.1)$ & $32(1.4)$ & $781(2.4)$ \\
\hline $\begin{array}{l}\text { Density (/100 years } \\
\text { observation, } 95 \% \mathrm{CI})\end{array}$ & $0.91(0.79-1.03)$ & $0.65(0.62-0.69)$ & $0.91(0.77-1.07)$ & $0.61(0.56-0.66)$ & $0.78(0.55-1.10)$ & $0.67(0.62-0.71)$ \\
\hline \multicolumn{7}{|l|}{ Aseptic revision } \\
\hline Crude incidence, number (\%) & $128(1.2)$ & $833(1.4)$ & $83(1.3)$ & $301(1.2)$ & $14(0.6)$ & $448(1.4)$ \\
\hline $\begin{array}{l}\text { Density (/100 years } \\
\text { observation, } 95 \% \mathrm{CI})\end{array}$ & $0.52(0.44-0.62)$ & $0.38(0.36-0.41)$ & $0.54(0.44-0.67)$ & $0.36(0.32-0.40)$ & $0.34(0.20-0.58)$ & $0.38(0.35-0.42)$ \\
\hline \multicolumn{7}{|l|}{ Septic revision } \\
\hline Crude incidence, number $(\%)$ & $95(0.9)$ & $585(1.0)$ & $57(0.9)$ & $214(0.9)$ & $18(0.8)$ & $333(1.0)$ \\
\hline $\begin{array}{l}\text { Density (/100 years } \\
\text { observation, } 95 \% \mathrm{CI})\end{array}$ & $0.39(0.32-0.47)$ & $0.27(0.25-0.29)$ & $0.36(0.28-0.47)$ & $0.25(0.22-0.29)$ & $0.44(0.28-0.70)$ & $0.28(0.26-0.32)$ \\
\hline \multicolumn{7}{|l|}{ Reasons for revision, number $(\%)$} \\
\hline Infection & $95(42.6)$ & $585(41.3)$ & $57(40.7)$ & $214(41.6)$ & $18(56.3)$ & $333(42.6)$ \\
\hline Instability & $57(25.6)$ & $255(18.0)$ & $45(32.1)$ & $93(18.1)$ & $1(3.1)$ & $133(17.0)$ \\
\hline Pain & $43(19.3)$ & $271(19.1)$ & $27(19.3)$ & $87(16.9)$ & $9(28.1)$ & $149(19.1)$ \\
\hline Arthrofibrosis & $27(12.1)$ & $149(10.5)$ & $15(10.7)$ & $47(9.1)$ & $5(15.6)$ & $82(10.5)$ \\
\hline Aseptic loosening & $18(8.1)$ & $233(16.4)$ & $8(5.7)$ & $97(18.8)$ & $4(12.5)$ & $123(15.7)$ \\
\hline Hematoma/seroma & $9(4.0)$ & $36(2.5)$ & $4(2.9)$ & $15(2.9)$ & $2(6.3)$ & $21(2.7)$ \\
\hline Wound drainage & $8(3.6)$ & $30(2.1)$ & $5(3.6)$ & $10(1.9)$ & $2(6.3)$ & $19(2.4)$ \\
\hline $\mathrm{PF}$ joint malfunction & $3(1.3)$ & $22(1.6)$ & $1(0.7)$ & $5(1.0)$ & $1(3.1)$ & $14(1.8)$ \\
\hline Wound dehiscence & $3(1.3)$ & $15(1.1)$ & $1(0.7)$ & $6(1.2)$ & $1(3.1)$ & $9(1.2)$ \\
\hline Failed extensor mechanism & $3(1.3)$ & $10(0.7)$ & $3(2.1)$ & $3(0.6)$ & $0(0.0)$ & $2(0.3)$ \\
\hline Femoral fracture & $2(0.9)$ & $23(1.6)$ & $2(1.4)$ & $12(2.3)$ & $0(0.0)$ & $11(1.4)$ \\
\hline Ingrowth failure & $2(0.9)$ & $9(0.6)$ & $0(0.0)$ & $4(0.8)$ & $0(0.0)$ & $1(0.1)$ \\
\hline Polyethylene insert wear & $2(0.9)$ & $24(1.7)$ & $1(0.7)$ & $9(1.7)$ & $0(0.0)$ & $13(1.7)$ \\
\hline Osteolysis & $2(0.9)$ & $28(2.0)$ & $2(1.4)$ & $6(1.2)$ & $0(0.0)$ & $21(2.7)$ \\
\hline Synovial impingement & $2(0.9)$ & $9(0.6)$ & $2(1.4)$ & $2(0.4)$ & $0(0.0)$ & $7(0.9)$ \\
\hline Tibial fracture & $0(0.0)$ & $5(0.4)$ & $0(0.0)$ & $1(0.2)$ & $0(0.0)$ & $4(0.5)$ \\
\hline Other & $17(7.6)$ & $80(5.6)$ & $13(9.3)$ & $22(4.3)$ & $3(9.4)$ & $44(5.6)$ \\
\hline
\end{tabular}

HXLPE $=$ highly crosslinked polyethylene; $\mathrm{CI}=$ confidence interval; $\mathrm{PF}=$ patellofemoral.

limitation of our study could be the lack of radiological, functional, or patient-reported outcomes. However, revision can occur as a consequence of wear, which HXLPE was designed to address. Each implant manufacturer uses a unique proprietary method to crosslink polyethylene. The results of our study pertain primarily to only two 


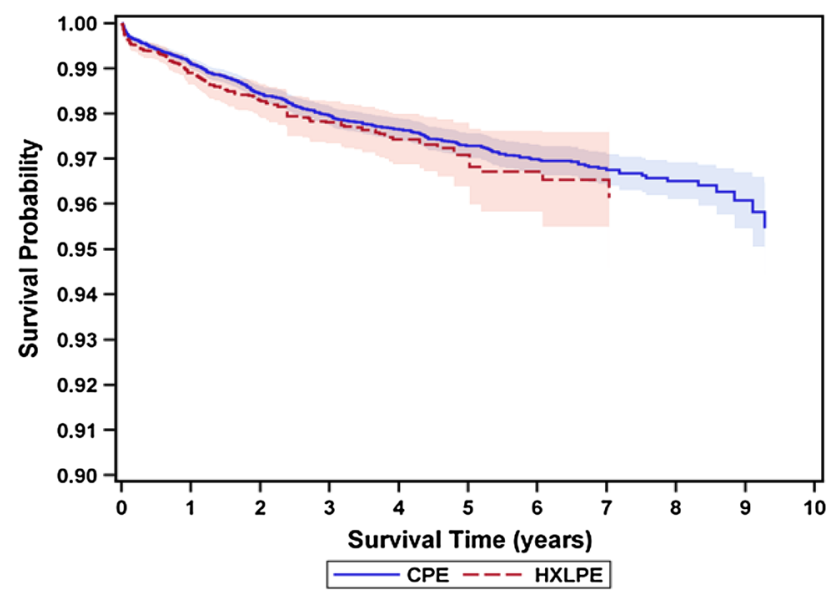

Fig. 2 Kaplan-Meier survival estimates and 95\% CIs by insert material for the Zimmer NexGen cohort are displayed. $\mathrm{CPE}=$ conventional polyethylene, $\mathrm{HXLPE}=$ highly crosslinked polyethylene.

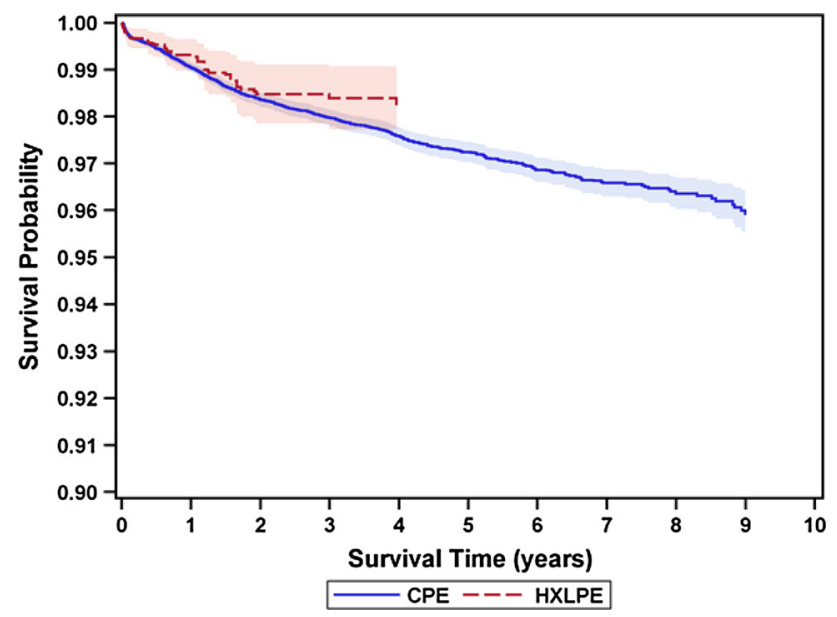

Fig. 3 Kaplan-Meier survival estimates and 95\% CIs by insert material for the DePuy PFC cohort are displayed. CPE = conventional polyethylene, HXLPE = highly crosslinked polyethylene.

HXLPE formulations used in two TKA designs, one from Zimmer and one from DePuy; thus, the findings may or may not apply to other HXLPE formulations of other implant manufacturers or to other implant designs. A final limitation of this study is our less than 10 years followup.

In comparing our study findings with single-center studies [6, 16], results were similar in not identifying major differences in CoCR-conventional polyethylene versus CoCr-HLXPE bearings. The results of our study also confirm earlier published findings from a large populationbased study with shorter followup [9]. However, our findings differ from those reported by the Australian Orthopedic Association National Joint Replacement Registry, which reported a lower risk of revision in TKAs using HXLPE [4]. At 5 years followup, the Australian Registry reported a $2.5 \%$ cumulative percent revision for HXLPE compared with $4 \%$ for those with conventional polyethylene, whereas in our study, cumulative incidence of revision for XLPE was $3.1 \%$ versus $2.7 \%$ for conventional polyethylene. The Australian Registry also reported that revision rates were prosthesis-dependent with no difference reported for the Triathalon implant (Stryker, Mahwah, NJ, USA) and the posterior-stabilized NexGen (Zimmer, Warsaw, IN, USA) but lower revision rates for HXLPE minimally stabilized Natural Knee II (Zimmer) and NexGen implants. In our study, we did not find a prosthesis brand effect; however, our subgroup sample sizes were small. Differences in our findings and those of the Australian registry are most likely related to variation in prostheses selection, which is more diverse in Australia than in our integrated healthcare system. Differences in results could also be related to variation in US versus Australian patient characteristics, surgical practices, and hospital settings, among other factors.

In vitro, the fatigue and fracture behavior of polyethylene are negatively impacted by radiation crosslinking [5]. There is a concern that the reduction in fracture toughness could lead to fatigue failure of tibial polyethylene inserts. Because TKA tibial inserts are subjected to higher contact stresses than THA liners, they are, in theory, more susceptible to delamination, fatigue wear, and pitting. Potentially vulnerable regions of tibial liners include areas with reduced thickness to permit locking of the inserts within the metal tibial trays and the tibial post in posteriorstabilized implants. In the current study, there were no observed failures of the HXLPE tibial inserts from either dissociation or from component fracture, suggesting this may not be an issue. However, longer followup is necessary to adequately evaluate this theoretical concern.

In summary, our study did not find differences in risk of revision for HXLPE compared with conventional polyethylene tibial inserts. Clinicians should consider the increased cost and lack of available evidence of performance beyond 10 years in selecting HXLPE for TKA. Continuous monitoring of this new technology is necessary, both to determine the longer-term outcomes of these bearings in TKA and their interactions with the wide range of implant brands where they could be used.

Acknowledgments We acknowledge all the Kaiser Permanente orthopaedic surgeons who contribute to the total joint replacement registry and the Surgical Outcomes and Analysis Department, which coordinates registry operations.

\section{References}

1. Australian Orthopaedic Association National Joint Replacement Registry. Annual Report. Adelaide, Australia: AOA; 2010. 
2. Australian Orthopaedic Association National Joint Replacement Registry. Annual Report. Adelaide, Australia: AOA; 2011.

3. Australian Orthopaedic Association National Joint Replacement Registry. Annual Report. Adelaide, Australia: AOA; 2012.

4. Australian Orthopaedic Association National Joint Replacement Registry. Annual Report. Adelaide, Australia: AOA; 2013.

5. Bradford L, Baker D, Ries MD, Pruitt LA. Fatigue crack propagation resistance of highly crosslinked polyethylene. Clin Orthop Relat Res. 2004;429:68-72.

6. Hodrick JT, Severson EP, McAlister DS, Dahl B, Hofmann AA. Highly crosslinked polyethylene is safe for use in total knee arthroplasty. Clin Orthop Relat Res. 2008;466:2806-2812.

7. Hong G. Marginal mean weighting through stratification: adjustment for selection bias in multilevel data. J Educ Behav Stat. 2010;35:499-531.

8. Hong G. Marginal mean weighting through stratification: a generalized method for evaluating multivalued and multiple treatments with nonexperimental data. Psychol Methods. 2012;17:44-60.

9. Inacio MC, Cafri G, Paxton EW, Kurtz SM, Namba RS. Alternative bearings in total knee arthroplasty: risk of early revision compared to traditional bearings: an analysis of 62,177 primary cases. Acta Orthop. 2013;84:145-152.

10. Kurtz S. The UHMWPE Biomaterials Handbook: Ultra-high Molecular Weight Polyethylene in Total Joint Replacement and Medical Devices. 2nd ed. Burlington, MA, USA: Academic Press; 2009.

11. Kurtz S, Ong K, Lau E, Mowat F, Halpern M. Projections of primary and revision hip and knee arthroplasty in the United States from 2005 to 2030. J Bone Joint Surg Am. 2007;89:780785 .

12. Kurtz SM, Gawel HA, Patel JD. History and systematic review of wear and osteolysis outcomes for first-generation highly crosslinked polyethylene. Clin Orthop Relat Res. 2011;469:22622277.

13. Kuzyk PR, Saccone M, Sprague S, Simunovic N, Bhandari M, Schemitsch EH. Cross-linked versus conventional polyethylene for total hip replacement: a meta-analysis of randomised controlled trials. J Bone Joint Surg Br. 2011;93:593-600.

14. Lee EW, Wei LJ, Amato DA. Cox-type regression analysis for large number of small groups of correlated failure time observations. In: Klein JP, Goel PK, eds. Survival Analysis: State of the Art. Dordrecht, The Netherlands: Kluwer; 1992.

15. McKnulty D, Swope S. The effect of crosslinking UHMWPE on in-vitro wear rates of fixed and mobile bearing knees. In: Kurtz S, Gsell R, Martell J, eds. Highly Crosslinked and Thermally Treated Ultra-high Molecular Weight Polyethylene for Joint Replacements. West Conshohocken, PA, USA: American Society for Testing and Materials; 2004.
16. Minoda $\mathrm{Y}$, Kobayashi A, Iwaki H, Iwakiri K, Inori F, Sugama R, Ikebuchi M, Kadoya Y, Takaoka K. In vivo analysis of polyethylene wear particles after total knee arthroplasty: the influence of improved materials and designs. J Bone Joint Surg Am. 2009;91(Suppl 6):67-73.

17. Mu Z, Tian J, Wu T, Yang J, Pei F. A systematic review of radiological outcomes of highly cross-linked polyethylene versus conventional polyethylene in total hip arthroplasty. Int Orthop. 2009;33:599-604.

18. Muratoglu OK, Bragdon CR, Jasty M, O'Connor DO, Von Knoch RS, Harris WH. Knee-simulator testing of conventional and cross-linked polyethylene tibial inserts. $J$ Arthroplasty. 2004;19:887-897.

19. Muratoglu OK, Rubash HE, Bragdon CR, Burroughs BR, Huang A, Harris WH. Simulated normal gait wear testing of a highly cross-linked polyethylene tibial insert. $J$ Arthroplasty. 2007;22:435-444.

20. Nakashima Y, Sato T, Yamamoto T, Motomura G, Ohishi M, Hamai S, Akiyama M, Hirata M, Hara D, Iwamoto Y. Results at a minimum of 10 years of follow-up for AMS and PerFix HA-coated cementless total hip arthroplasty: impact of crosslinked polyethylene on implant longevity. J Orthop Sci. 2013;18:962-968.

21. Owens WD, Felts JA, Spitznagel EL Jr. ASA physical status classifications: a study of consistency of ratings. Anesthesiology. 1978;49:239-243.

22. Paxton EW, Inacio MC, Khatod M, Yue EJ, Namba RS. Kaiser Permanente National Total Joint Replacement Registry: aligning operations with information technology. Clin Orthop Relat Res. 2010;468:2646-2663.

23. Paxton EW, Inacio MCS, Kiley ML. The Kaiser Permanente implant registries: effect on patient safety, quality improvement, cost effectiveness, and research opportunities. Perm J. 2012;16:33-40.

24. Paxton EW, Kiley ML, Love R, Barber TC, Funahashi TT, Inacio MC. Kaiser Permanente implant registries benefit patient safety, quality improvement, cost-effectiveness. Jt Comm J Qual Patient Saf. 2013;39:246-252.

25. Paxton EW, Namba RS, Maletis GB, Khatod M, Yue EJ, Davies M, Low RB Jr, Wyatt RW, Inacio MC, Funahashi TT. A prospective study of 80,000 total joint and 5000 anterior cruciate ligament reconstruction procedures in a community-based registry in the United States. J Bone Joint Surg Am. 2010;92(Suppl 2):117-132.

26. Rodriguez JA. Cross-linked polyethylene in total knee arthroplasty: in opposition. J Arthroplasty. 2008;23(Suppl): 31-34.

27. Rubin DB. Multiple Imputation for Nonresponse in Surveys. New York, NY, USA: John Wiley \& Sons, Inc; 1987. 